\title{
PERANCANGAN SISTEM PENDUKUNG KEPUTUSAN DALAM MEMBACA CEPAT UNTUK MENEMUKAN IDE POKOK PARAGRAF
}

\author{
Nunu Kustian ${ }^{1}$, Wanti Rahayu ${ }^{2}$, Retna Ningsih ${ }^{3}$ \\ FTMIPA, Universitas Indraprasta PGRI ${ }^{1,2,3}$ \\ kustiannunu@gmail.com,wanti.reiku@gmail.com, ennatatto@gmail.com
}

\begin{abstract}
Abstrak
Sistem pendukung Keputusan (SPK) merupakan sistem yang mampu memberikan penilaian terhadap alternatif guna untuk membantu dalam mengambil keputusan. Sekolah Menengah Pertama pada pelajaran Bahasa Indonesia khususnya dalam menemukan ide pokok paragraf menjadi hal yang masih diperhatikan oleh guru bahasa Indonesia karena banyak siswa yang mengalami kesulitan dan kurang pahamnya siswa dalam menemukan ide pokok paragraf. Sistem yang dirancang dengan menggunakan metode Simple Additive Weighting (SAW) yang akan bekerja untuk menentukan teknik membaca cepat yang dipilih dalam menemukan ide pokok paragraf. Analisis data yaitu dengan cara menganalisa angket dalam bentuk pertanyaan didalam kuesioner yang diberikan kepada siswa dengan populasi sebanyak 36 siswa. Sistem yang dibangun dapat membantu menyelesaikan dan mempercepat teknik yang dipilih dalam menemukan ide pokok paragraf.

Kata Kunci : Sistem Pendukung Keputusan, Simple Additive Weighting, Membaca Cepat, Ide Pokok Paragraf
\end{abstract}

\begin{abstract}
Decision Support Systems (DSS) is a system that can assess the alternatives in order to help with the decision-making. Indonesian language lesson in Junior HighSchool, especially the topic of finding the main idea ina paragraph is still a focusIndonesian teachers keep as many students still have difficulty in understandinghow to find the main idea in a paragraph. Systems designed by using the method of Simple Additive Weighting (SAW) will perform to determine the selected speed reading techniques in finding the main idea in a paragraph. The data are analyzedbyevaluating the questionnaires in the form of questions given to population consisting of 36 students. The built systems help to resolve and speed up the selected techniques for finding a main idea in a paragraph.
\end{abstract}

Keywords : Decision Support Systems, Simple Additive Weighting, Speed Reading, the Main Idea ina Paragraph

\section{PENDAHULUAN}

\section{Latar Belakang}

Di era globalisasi ini perkembangan teknologi perangkat lunak melaju dengan sangat pesat, ini dapat ditinjau dari munculnya berbagai aplikasi. Dari pesatnya perkembangan ini perluasan pemanfaatan komputer yang semula dimanfaatkan sedikit orang, kini menjadi dimanfaatkan banyak orang termasuk Sekolah Menengah Pertama (SMP). Hal ini mengakibatkan perubahan pada berbagai bidang kehidupan seperti halnya dalam proses pengambilan sebuah keputusan, terkadang keputusan yang dibuat oleh seseorang atau sekelompok kurang akurat dalam penilaiannya. Begitu juga terhadap pembelajaran Bahasa Indonesia dalam menemukan ide pokok paragraf, banyak siswa Sekolah Menengah Pertama yang sulit dan kurang paham nya mereka dalam menemukan ide pokok paragraf. Sehingga mereka membutuhkan teknik membaca cepat dalam membantu menemukan ide pokok paragraf. Dalam penelitian ini menggunakan objek SMP kelas VIII SMPN 131 Jakarta yang diharapkan dapat membantu mereka dalam menemukan ide pokok paragraf dengan teknik membaca cepat yang sesuai dengan keadaan di kelas. Untuk memudahkan dan mempercepat pemilihan dalam menemukan ide pokok 
paragraf, maka dibutuhkan sebuah sistem yang dapat menyeleksi teknik membaca cepat tersebut secara obyektif agar didapatkan sebuah hasil keputusan yang cepat, tepat, dan akurat. Membaca cepat menurut artinya membaca yang mengutamakan kecepatan dengan tidak mengabaikan pemahamannya [4].Biasanya kecepatan itu dikaitkan dengan tujuan membaca, keperluan, dan bahan bacaan. Artinya, seorang pembaca cepat yang baik, tidak menerapkan kecepatan membacanya yang membuat mata kita bergerak dengan cepat, melihat, memperhatikan bahan tertulis untuk mecari daan mendapatkan informasi. Sementara referensi [5] membaca cepat adalah suatu keterampilan untuk memperoleh informasi dari sumber manapun karena ada satu kemampuan yang dituntut dan tidak berubah yaitu kemampuan membaca dari si pencari informasi.

Sistem tersebut adalah sebuah sistem pendukung keputusan dengan menggunakan Simple Additive Weighting (SAW) yang akan bekerja untuk menentukan teknik membaca cepat yang dipilih dalam menemukan ide pokok paragraf.Referensi[2] menyatakan Simple Additive Weighting (SAW) dikenal dengan metode penjumlahan terbobot. Konsep dasar metode SAW adalah metode mencari penjumlahan terbobot dari rating kinerja setiap alternatif pada semua atribut.

\section{Tujuan Penelitian}

Untuk mengetahui penggunaan sistem pendukung keputusan dapat membantu dalam menemukan ide pokok paragraf dengan teknik membaca cepat yang dipilih.

\section{Manfaat Penelitian}

Manfaat yang diharapkan akan diperoleh dari penelitian ini adalah sebagai berikut:

Peneliti: Penelitian ini memberikan manfaat untuk peneliti yaitu berupa pemahaman yang lebih lanjut mengenai ilmu yang dipelajari serta sebagai tolak ukur penerapan ilmu pengetahuan ke dalam permasalahan yang sebenarnya.

Siswa: Membantu siswa dalam menemukan ide pokok paragraf dengan sistem pendukung keputusan terhadap teknik membaca cepat yang dipilih.

\section{METODE PENELITIAN}

\section{Rancangan Penelitian}

Rancangan penelitian ini adalah penelitian kuantitatif yang digunakan untuk meneliti pada populasi atau sampel tertentu yang menggambarkan suatu gejala dari data yang bersifat kuantitatif. Data yang bersifat kuantitatif yaitu kemampuan Kecepatan Efektif Membaca (KEM) yang dideskripsikan atau dicari skor reratanya. Hasil skor tersebut juga dapat dikategorikan sehingga frekuensi dan presentase yang diharapkan.

\section{Teknik Pengumpulan Data}

Pengumpulan data merupakan langkah yang sangat penting dalam metode penelitian. Penelitian ini menggunakan metode penelitian kuantitatif dan kualitatif. Data kuantitatif diperoleh dari hasil observasi siswa SMPN 131 Jakarta Kelas VIII. Responden dari penelitian ini adalah 36 siswa. Jumlah siswa yang dijadikan sampel dari penelitian ini diambil dari teknik Penelitian Tindakan Kelas (PTK) atau Classroom Action Research (CAR).

\section{Teknik Analisis Data}

Analisis data pada penelitian ini menggunakan teknik kuantitatif. Teknik penganalisis data kuantitatif pada penelitian ini digunakan untuk menganalisis hasil tes membaca cepat berupa nilai rerata. Untuk memperoleh data tentang kemampuan membaca cepat peneliti menggunakan data dari hasil evaluasi atau teknik ayng berikan kepada peserta didik. Untuk mengukur Kecepatan Efektif Membaca (KEM) seseorang, perlu dilakukan hal-hal berikut:
a. Pengumpulan data dengan menghitung nilai kecepatan 
membaca siswa dan pemahaman siswa dengan rumus:

1. Rumus Kecepatan Membaca

$$
\text { Kecepatan Membaca }=\frac{\mathrm{K}}{\mathrm{Wd}} \times 60 \text { detik }
$$

2. Kemampuan Pemahaman

$$
\text { Pemahaman Membaca }=\frac{B}{S I} \times 100 \%
$$

3. Kecepatan Efektif Membaca (KEM)

\section{$K E M=$ Kecepatan Membaca $\times$ Pemahaman Membaca}

b. Mencari ukuran pemusatan. Nilai ukuran pemusatan diperoleh dengan mencari mean atau nilai rata-rata dari Kecepatan Efektif Membaca (KEM) dari seluruh sampel. Rumus yang dipakai adalah:

$$
M x=\frac{\sum f x}{N}
$$

Keterangan:

Mx : Mean (nilai rata-rata)

$\sum \mathrm{fx}$ : Jumlah nilai tes kecepatan efektif membaca

$\mathrm{N}$ : Jumlah siswa

Hasil presentase kemampuan siswa tiap-tiap tes ini akan memberikan gambaran mengenai sejauh mana tingkat Kecepatan Efektif Membaca (KEM) siswa.

Analisis data dilakukan setelah tahapan penelitian dilaksanakan. Didalam analisis data ini yang dilakukan dalam penelitian adalah menganalisis data dari tahapan penelitian yang telah dilakukan, yaitu menganalisa angket pengujian sistem yang digunakan dalam penelitian.

\section{Penerapan Metode Simple Additive Weigthing \\ Merupakan metode Simple Additive Weighting (SAW). Pada tahap ini merupakan bagian dari tahapan pengembangan sistem.}

Perancangan Sistem Pendukung Keputusan Hal yang dilakukan pada tahap ini adalah mengimplementasikan hasil penelitian yang dilakukan. Dalam perancangan perangkat lunak ini hal-hal yang akan dilakukan meliputi input bobot kriteria dan menghitung tiap-tiap alternatif.

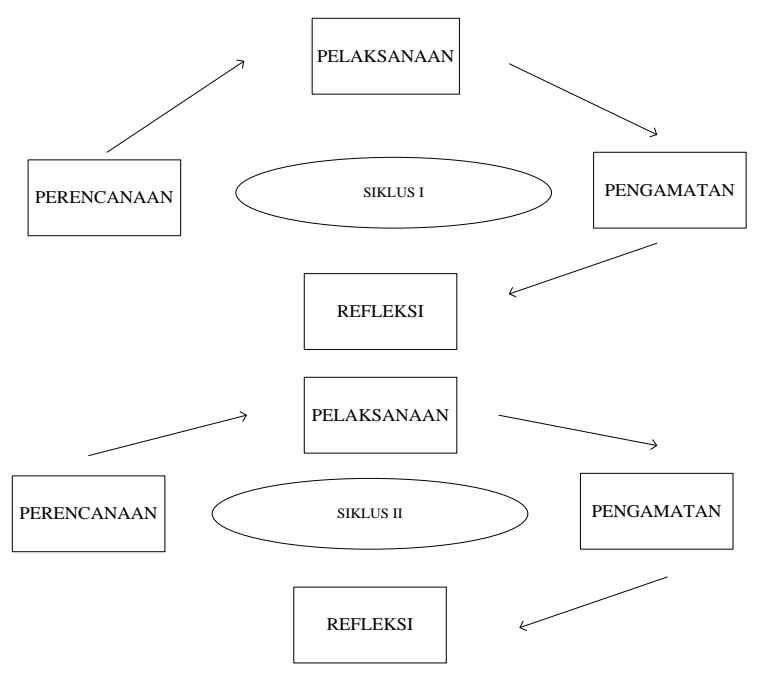

\section{Gambar 1. Design Penelitian Tindakan Kelas [7]}

\section{Pedoman Penilaian}

Untuk mengukur hasil penelitian ini, peneliti membuat pedoman penilaian yaitu sebagai berikut:

Tabel 1. Pedoman Penilaian Kecepatan Efektif Membaca (KEM)

\begin{tabular}{lcl}
\hline No & Kecepatan Efektif Membaca & \multicolumn{1}{c}{ Kategori } \\
\hline 1. & $189-227 \mathrm{Kpm}$ & Sangat Cepat \\
2. & $150-188 \mathrm{Kpm}$ & Cepat \\
3, & $111-149 \mathrm{Kpm}$ & Sedang \\
4. & $72-110 \mathrm{Kpm}$ & Lambat \\
5. & $33-71 \mathrm{Kpm}$ & Sangat Lambat \\
\hline $\begin{array}{l}\text { Sumber: } \\
\text { (KEM) }\end{array}$ & &
\end{tabular}

Indikator keberhasilan dalam penelitian ini meliputi indikator hasil dari penggunaan 
teknik membaca cepat yang dipilih melalui metode SAW dalam meningkatkan kemampuan mencari ide pokok paragraf peserta didik kelas VIII.1 131 SMPN Jakarta. Menurut referensi [1], tingkat keberhasilan dalam proses pembelajaran dikatakan berhasil dapat dilihat dari tingkatan sebagai berikut:

1. Istimewa/maksimal: apabila seluruh bahan pelajaran dapat dikuasai oleh siswa.

2. Baik sekali/optimal: apabila sebagian besar (76\% s.d. 99\%) bahan pelajaran dapat dikuasai oleh siswa.

3. Baik/minimal: apabila bahan pelajaran yang diajarkan hanya $(60 \%$ s.d. $76 \%)$ saja yang dikuasai oleh siswa.

4. Kurang: apabila bahan pelajaran yang diajarkan kurang dari $60 \%$ dikuasai oleh siswa.

Dengan melihat data yang terdapat dalam format daya serap siswa dalam pelajaran dan presentase keberhasilan siswa dalam mencapati target keberhasilan yang telah ditentukan, maka kita dapat mengetahui keberhasilan dari proses pembelajaran yang dilakukan oleh guru terhadap siswa. Maka peneliti mengambil kesimpulan jika rata-rata siswa didalam kelas telah menguasai $80 \%$ materi dan dengan mendapat nilai KKM atau lebih dari 70, maka dapat dikatakan telah berhasil dengan baik karena pertimbangan dari hasil persentase di atas. Dalam Pemetaan Kompetensi Mata Pelajaran Bahasa Indonesia oleh Dinas Pendidikan ditetapkan kompetensi dasar kelas VIII yang berbunyi: Menyimpulkan isi suatu teks dengan membaca cepat 250 kata per menit dengan indikator bahwa siswa mampu menjawab dengan benar $75 \%$ dari jumlah pertanyaan yang disediakan. Siswa tingkat SMP kelas
VIII, diharapkan mampu mencapai KEM sebesar 150-188 kpm dengan perhitungan $200 \times 75 \%=150 \mathrm{kpm}$ dan $250 \times 75 \%=188 \mathrm{kpm}(187,50 \mathrm{kpm})$.

\section{HASIL DAN PEMBAHASAN Siklus I}

Tes Kecepatan Efektif Maksimal pada siklus I membaca cepat dilaksanakan dengan menggunakan teknik skimming dan dan scanning untuk lebih memperjelas kesimpulan penelitian. Berikut data hasil tes kemampuan membaca siswa dengan teknik skimming.

Tabel 2. Hasil Tes Membaca Cepat Siklus I Teknik Skimming

\begin{tabular}{lllll}
\hline No & KEM & $\begin{array}{l}\text { Frekue } \\
\text { nsi }\end{array}$ & Persentase & Keterangan \\
\hline 1 & $\begin{array}{l}189-227 \\
\text { Kpm }\end{array}$ & 0 & $0 \%$ & sangat cepat \\
\hline 2 & $\begin{array}{l}150-188 \\
\text { Kpm }\end{array}$ & 4 & $11 \%$ & Cepat \\
\hline 3 & $\begin{array}{l}111-149 \\
\text { Kpm }\end{array}$ & 18 & $50 \%$ & Sedang \\
\hline 4 & $\begin{array}{l}72-110 \\
\text { Kpm }\end{array}$ & 14 & $39 \%$ & Lambat \\
\hline 5 & $\begin{array}{l}33-71 \\
\text { Kpm }\end{array}$ & 0 & $0 \%$ & sangat lambat \\
\hline Sumber: Data primer diolah, 2017 &
\end{tabular}

Hasil tes membaca cepat pada siklus I dengan menggunakan teknik skimming menunjukkan bahwa hasil rata-rata siswa dalam kecepatan membaca siswa teknik skimming adalah 121,10 atau termasuk dalam kategori sedang, hal ini menyatakan belum ada yang tuntas dalam kecepatan membaca pada siklus I dengan menggunakan teknik skimming namun mengalami peningkatan dari hasil tes prasiklus. Skor yang didapat dengan kategori sangat cepat (189-227 KPM) 0 siswa (0\%), kategori cepat (150-188 KPM) 4 siswa (11\%), kategori sedang (111-149 KPM) 18 siswa (22\%), kategori lambat (72-110 KPM) 14 siswa (39\%), dan kategori sangat lambat (33-71 KPM) 0 siswa $(0 \%)$. 


\section{Hasil Tes Scanning}

Berikut data hasil tes kemampuan siswa dengan menggunakan teknik scanning.

Tabel 3. Hasil Tes Membaca Cepat Siklus I Teknik Scanning

\begin{tabular}{clrrl}
\hline No & \multicolumn{1}{c}{ KEM } & Frekuensi & Persentase & Keterangan \\
\hline 1 & $\begin{array}{l}189-227 \\
\mathrm{Kpm}\end{array}$ & 0 & $0 \%$ & $\begin{array}{l}\text { sangat } \\
\text { cepat }\end{array}$ \\
\hline 2 & $\begin{array}{l}150-188 \\
\mathrm{Kpm}\end{array}$ & 7 & $19 \%$ & cepat \\
\hline 3 & $\begin{array}{l}111-149 \\
\mathrm{Kpm}\end{array}$ & 14 & $39 \%$ & sedang \\
\hline 4 & $72-110 \mathrm{Kpm}$ & 15 & $42 \%$ & lambat \\
\hline 5 & $33-71 \mathrm{Kpm}$ & 0 & $0 \%$ & $\begin{array}{l}\text { sangat } \\
\text { lambat }\end{array}$ \\
\hline
\end{tabular}

Sumber: Data primer diolah, 2017

Hasil membaca cepat dengan teknik scanning memperoleh skor kategori sangat cepat (189-227 KPM) 0 siswa (0\%), kategori cepat (150-188) 7 siswa (19\%), kategori sedang (111-149 KPM) 14 siswa (39\%), kategori lambat (72-110 KPM) 15 siswa (42\%), dan kategori sangat lambat (33-71 KPM) 0 siswa (0\%).

Dari jumlah keseluruhan siswa yaitu 36 siswa, 7 siswa dinyatakan cepat dalam melakukan teknik scanning untuk menemukan ide pokok paragraf dimana rata-rata yang diperoleh yaitu 120, 75 termasuk ke dalam kategori sedang. Sama hal dengan teknik skimming yang mengalami peningkatan.

\section{Flowchart Perhitungan Metode SAW}

Flowchart perhitungan metode SAW adalah deskripsi dari langkah-langkah pada metode Simple Additive Weighting (SAW) yang terjadi pada sistem yang merupakan proses pengambilan keputusan untuk menentukan alternatif terbaik dengan urutan ranking dari nilai terbesar pada setiap alterantif yang telah ditentukan. Langkah-langkah tersebut dapat dilihat pada gambar 2 dibawah ini yang merupakan flowchart perhitungan metode SAW yang dibangun.

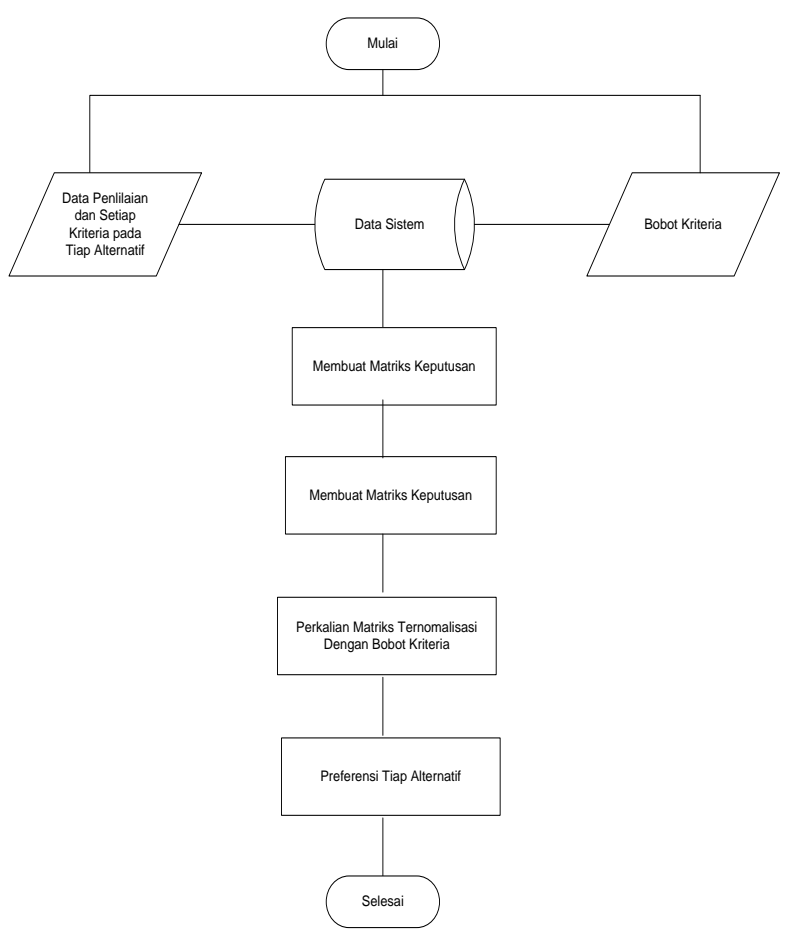

\section{Gambar 1. Flowchart Perhitungan Metode SAW}

\section{Perancangan Subsistem Manajemen Dialog}

Merancang subsistem dialog merupakan rancangan menu sistem yang bersifat user friendly sehingga decision maker (pengguna sistem) paham dalam memilih setiap menu-menu pilihan yang terdapat pada sistem.

\section{Struktur Menu}

Tujuan perancangan adalah untuk membuat panduan desain pada tahap implementasi mengenai rancangan desain dari sistem yang akan dibangun.

Struktur menu Sistem Pemilihan dalam menemukan ide pokok paragraf dapat dilihat pada tampilan menu Home dan Menu Administrator pada gambar 3 dan 4 berikut ini: 


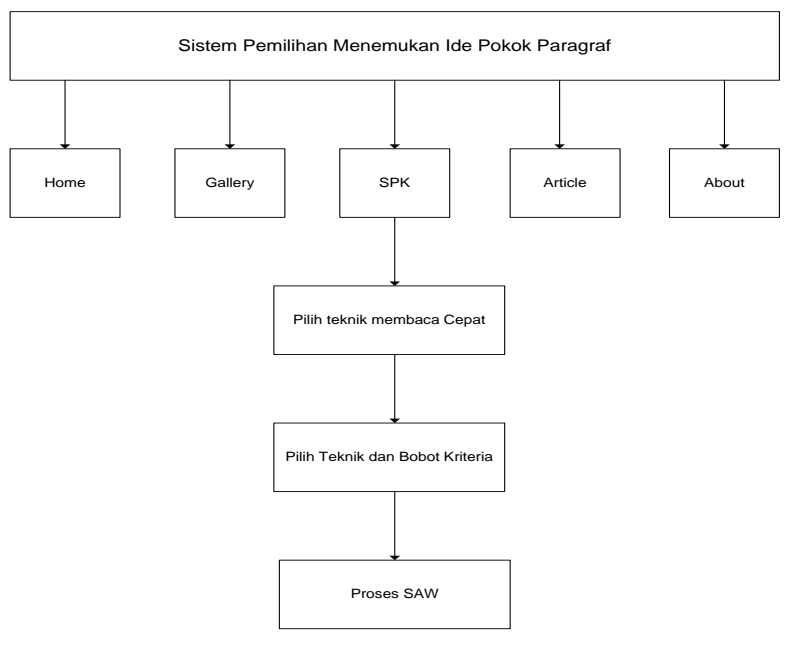

Gambar 2. Struktur Menu pada Tampilan Home

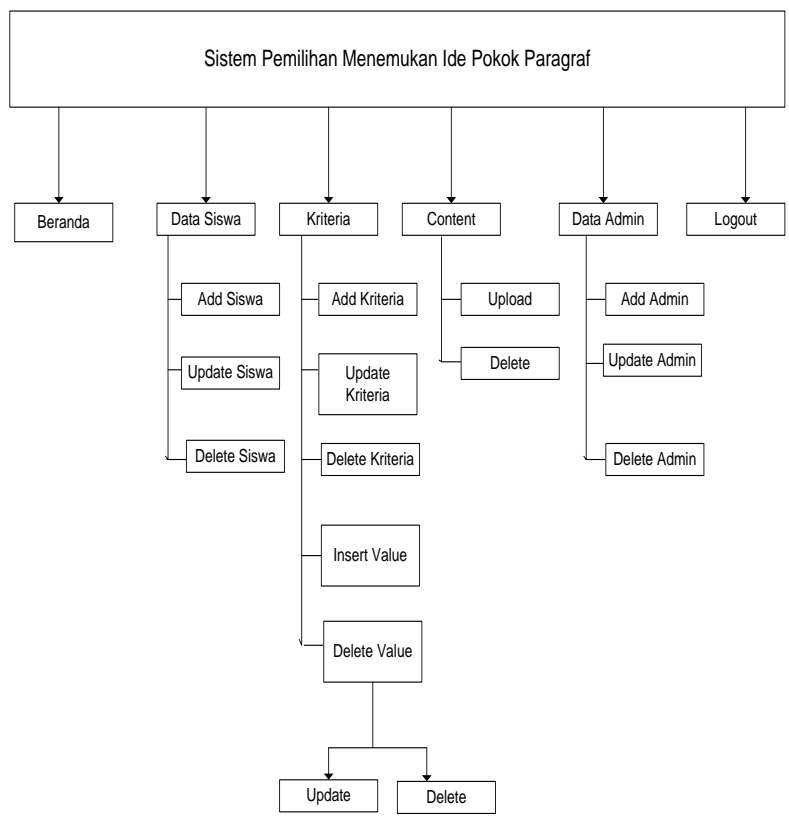

Gambar 3. Struktur Menu pada Tampilan Menu Administrator

\section{Perancangan Antar Muka (Interface)}

Perancangan antar muka sistem bertujuan untuk menggambarkan sistem yang akan dibangun. Berikut ini adalah perancangan dari antar muka pada sistem pemilihan menemukan ide pokok paragraf.

\section{Rancangan Menu Home}

Rancangan menu home berisi form yang menjelaskan tentang awal dari sistem pemilihan menemukan ide pokok paragraf menggunakan metode SAW (Simple Additive Weighting).

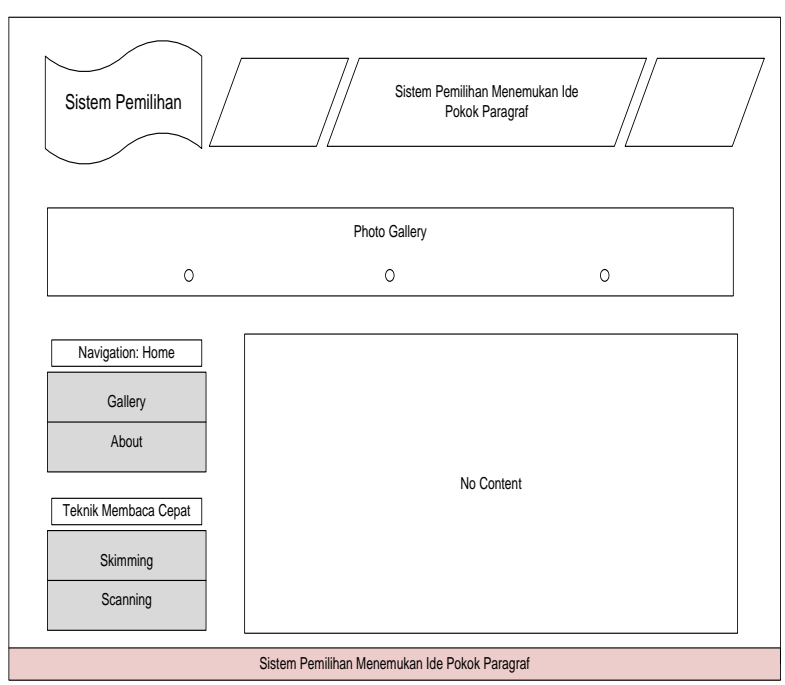

Gambar 4. Rancangan Menu Home

\section{Rancangan Menu Administrator}

Rancangan menu administrator merupakan halaman admin setelah admin atau Administrator melakukan login ke sistem pemilihan ide pokok paragraf.

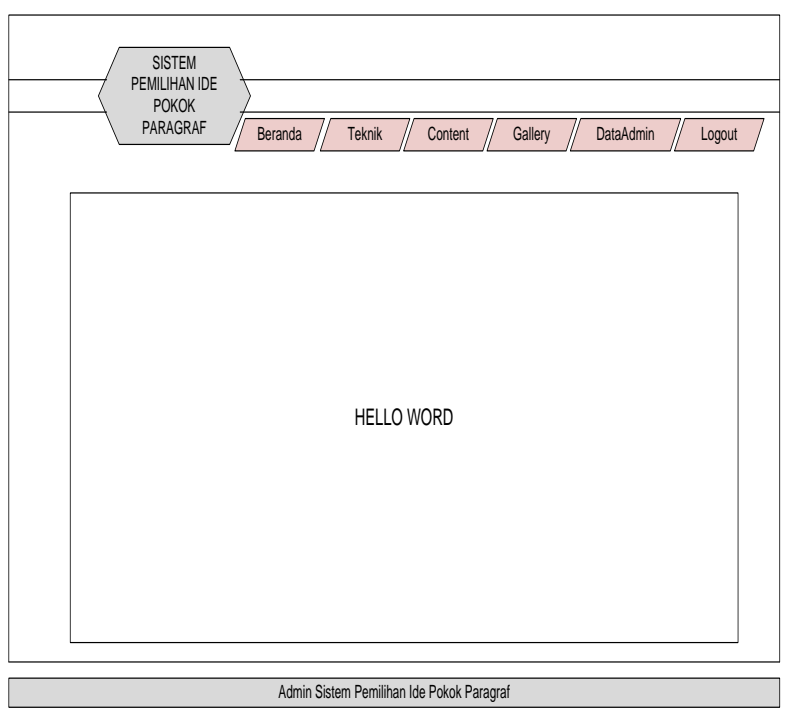

Gambar 5. Rancangan Menu Administrator 


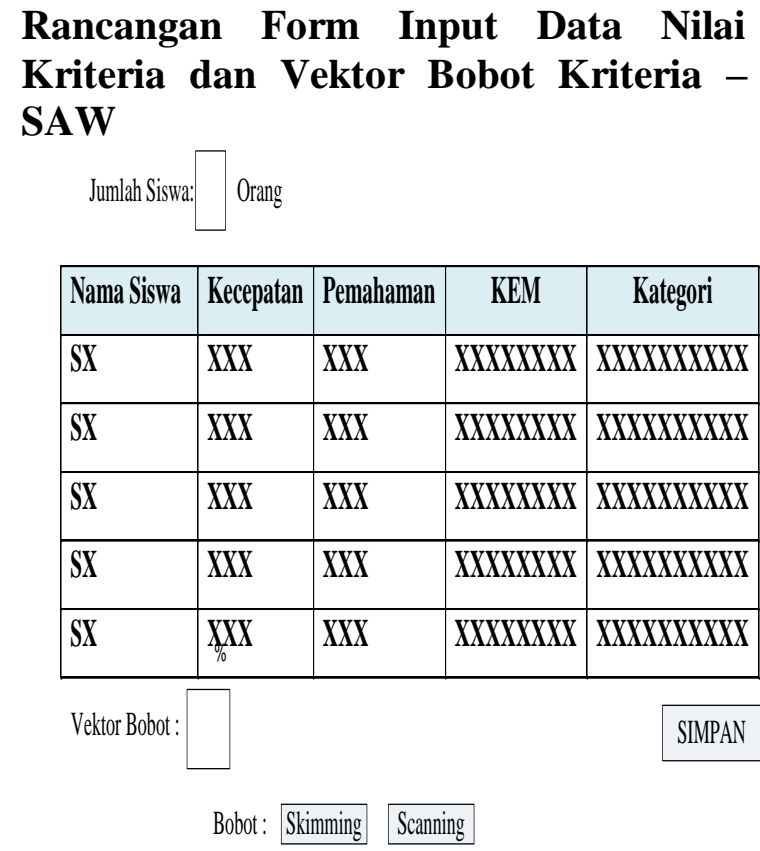

Gambar 6. Rancangan Form Input Data Nilai Kriteria dan Vektor Bobot Kriteria-SAW

\section{Rancangan Form Hitung Nilai Akhir SAW}

Hasil Pemilihan:

\begin{tabular}{|l|l|l|l|}
\hline Normalisasi & Perilaku & Kecepatan & Pemahaman \\
\hline SX & $\mathrm{XXX}$ & $\mathrm{XXX}$ & $\mathrm{XXXXXXXX}$ \\
\hline SX & $\mathrm{XXX}$ & $\mathrm{XXX}$ & $\mathrm{XXXXXXXX}$ \\
\hline SX & $\mathrm{XXX}$ & $\mathrm{XXX}$ & $\mathrm{XXXXXXXX}$ \\
\hline SX & $\mathrm{XXX}$ & $\mathrm{XXX}$ & $\mathrm{XXXXXXXX}$ \\
\hline SX & $\mathrm{XXX}$ & $\mathrm{XXX}$ & $\mathrm{XXXXXXXX}$ \\
\hline
\end{tabular}

Hitung

Bobot: $\quad$ cost benefit

\section{Gambar 7. Rancangan Form Hitung \\ Nilai Akhir SAW}

\section{SIMPULAN}

Berdasarkan hasil pengumpulan data dan pemrosesan, maka dapat disimpulkan:

1. Didapatkan teknik terpilih membaca cepat yang berpengaruh pada kelas VIII.1 SMPN 131 Jakarta dalam menemukan ide pokok paragraf yaitu teknik scanning berdasarkan hasil metode Simple Additive Weighting(SAW).

2. Terdapat pengaruh yang signifikan dalam proses pembelajaran membaca cepat menggunakan teknik skimming yaitu keseriusan siswa dalam mengerjakan tugas, dan keaktifan siswa dalam kerjasama kelompok mempunyai pengaruh besar dalam proses pembelajaran membaca cepat menggunakan teknik scanning. Hal ini terlihat dari hasil penggunaan metode Simple Additive Wrighting(SAW).

3. Sistem pendukung keputusan pemilihan ide pokok paragraf berhasil dirancang dalam bentuk sistem yang dapat membantu pengguna (decision maker) dalam memilih alternatif, kriteria, dan bobot.

\section{UCAPAN TERIMAKASIH}

Terimakasih kami ucapkan kepada DRPM Kemenristek Dikti yang telah memberikan bantuan sehinga penelitian ini dapat terlaksana dengan baik.

\section{DAFTAR PUSTAKA}

[1] Bahri Djamarah, S., "Psikologi Belajar", PT. Rineka Cipta. Jakarta. 2011.

[2] Kusumadewi, Sri danPurnomo, Hari, "Fuzzy Multi-Attribute Decision making", GrahaIlmu Yogyakarta. 2006.

[3] Nugraha, Bunafit, "Membuat Website Sendiri Dengan PHP-My SQL", Mediakita. 2009. 
[4] Nurhadi. Membaca Cepat dan Efektif. Bandung: Sinar Baru Algensindo. 2008.

[5] Subyantoro. Penelitian Tindakan Kelas (Edisi Revisi). Semarang: UNDIP. 2011.

[6] Sutarman,Pengantar Teknologi Informasi". Jakarta: Bumi Aksara. 2009.

[7] Putra Nusa, Metode Penelitian Kualitatif Pendidikan", Jakarta: Rajawali Press. 2012.
Web:

Diakses dari BSNP website:

http://bsnp-indonesia.org/wp-

content/uploads/kompetensi/Panduan_Um um_KTSP.pdf

(Diakses 16 Juli 2017)

https://luk.staff.ugm.ac.id/atur/bsnp/Perme ndikbud66-2013SPenilaian.pdf

(Diakses 16 Juli 2017) 